\title{
SELECTED ASPECTS OF DEVELOPMENT TOWARDS ENERGY EFFICIENT BUILDINGS
}

\author{
Dorota Wójcicka-Migasiuk', Magdalena Paśnikowska-Łukaszuk \\ 1 Fundamentals of Technology Faculty, Lublin University of Technology, Nadbystrzycka 38 Str., 20-618 Lublin, \\ Poland, e-mail: d.wojcicka-migasiuk@pollub.pl, pasnikowskamagdalena@gmail.com
}

Received: 2017.05.25

Accepted: 2017.08.01

Published: 2017.09.01

\begin{abstract}
The focal point is to present the areas where the technology in buildings can be supported by proper motivation and take substantial advantage measurable in technical units. The need to understand the integration between ecology, society, economy and technology is crucial when global improvements are the targets. These targets should consider urban environments as natural human settlement, in the understanding that accepts human psychological needs for wide and deep education, acquiring highly professional satisfaction without resigning from family style of life and leisure as natural. It is necessary to accept human production also in its advanced levels as a natural human activity and to combine it with the other afore-mentioned components of integration. Attention has been directed to clean energy certification in newly constructed objects and refurbished buildings, formation of owner's responsibility for the possessed goods and their best use in sustainable development. Particular attention has been drawn to the increasingly popular manner of using resources only if it is justified by proportionally very high advantages to the society. This has been presented with the examples of energy savings in low energy and passive buildings. Moreover, the examples show the ways of sustainable development which include the use of renewable energy, using coal only in collective industrial systems very restricted in terms of protection against pollution and uncontrolled use of energy, and similarly, of other conventional fuels, water and land.
\end{abstract}

Keywords: low energy buildings, thermal-visual measurements, biofuel, waste management aspects

\section{INTRODUCTION}

The idea of respect the resources can start from a proper management of waste which are consistently connected with human activity. Selection of waste, its proper treatment and use already bring a substantial input into the energy generation process. Nowadays, many methods of successful processing have been devised but still the prevailing amount of waste is maintained without any useful process. This consumptive and non-sustainable way of living becomes more and more harmful to our environment. The reasons for this problem can be identified in the lack of sufficient targeted education and motivation form proper use of waste. Many pro-ecological institutions work hard on introducing successful programs and methods for the motivation directed towards proper waste selection as part of the collection process. Nevertheless, there are still many decisive and opinion forming social environments where this outdated, conservative and harmful thinking of sole waste removal prevails. Improper waste removal results in discarding the waste directly in forests or in direct pollution of surface waters. The effects can occur in the form of forest fires or animal and people poisoning. The intensive monitoring of forests and other natural areas is more of a rescue method than the increase of motivation. That is why the extended obligatory system of waste segregation is simply necessary in the national practice. 
Respect to the resources is extended into energy availability and its preservation. This particular problem is distinctly the most important in buildings. Scientific recognition of this area has already been substantial but is still increasing considering the fact that new materials for construction, insulation, systems and even decorations are still being developed worldwide. Some directions of applied developments have been indicated by means of required certificates of energy efficiency in new and modernized buildings.

Energy saving undertakings are motivated not just by the energy saving but mostly by the total aspects of integrated ecology in sustainable development of humanity. Putting it into practice takes place in every small scale renovation or attempt towards the reduction of energy use, recycling of materials, creating employment opportunities, land preservation, total environment protection and improvement of social living conditions which can be understood very broadly.

It is comparatively easy to estimate the health damage caused by smoking cigarettes to smoker's family, but it is more difficult to indicate the effect on district inhabitants where waste is combusted in small household fireplaces or even in boilers fired with briquettes or chopped wood. This low emission can be smelled even in the radius of a kilometer from the spot. The ignorance of physics together with the ignorance of the environment may lead to detrimental effects- let us recall the famous London smog poisoning cases in 1952 or more recent smog in Kraków in 2015 [Wójcicka-Migasiuk, 2016].

\section{RESPECT TO THE RESOURCES}

German legislative system proves the estimation that about $60 \%$ of raw materials can be retrieved from proper waste treatment and its effective application. Such European countries as Kosovo, Montenegro, Liechtenstein, Cyprus and Malta produce the least amount of waste in relation to their population; tens of tons are produced by Czech, Estonia, Denmark, Slovakia and Ireland; about two hundred thousand of tons are produced by Poland, Italy, Sweden and Bulgaria; then Romania, Great Britain, France and Germany form the total European amount of $2.6 \mathrm{mln}$ tons yearly.

Pro-ecological behavior serves well for the national economy and enables to implement en- ergy saving technologies in practice. For example, the most common segregation into 3 fractions i.e.: dry, mixed and green by inhabitants, is time and cost effective, assuming that the first phase is accurate and totally effective. This proper fostering also enables the implementation of recycling processes, which can be mentioned on the example of polyethylene terephthalate. The first separation, carried out by enterprises, consists in the separation of white transparent material from blue or green dyed one. Then, granulate is generated as the raw material for the secondary production of new packaging, building insulation panels or fabrics.

The amount of energy savings from plastic recycling estimated from $1 \mathrm{t}$ of raw material amounts to $5774 \mathrm{kWh}$ or $2.510^{3} 1$ of natural oil and waste volume reduction of 22 sq. m. Another example is the secondary use of glass material in the form of fibers, foam glass and new cast. The idea of up-cycling is the new path of old household methods when things are given a new life after a renovation process or serve as an element with a new application. This is a very creative way of thinking connected with new methods of education when young people are fostered to figure out new forms and uses for waste elements of e.g. furniture, decorations, fabrics and all types of manufactured products, which develops early understanding of being sustainable. The last stage of using worn materials and products is incineration. This area is, in turn, an intermediate between waste treatment treated as alternative fuel and energy production. Calorific values are attractive economically and they can be listed as follows: plastics - 40-60 MJ/kg; spent oils -40 $\mathrm{MJ} / \mathrm{kg}$; chlorinated hydrocarbons - $27 \mathrm{MJ} / \mathrm{kg}$; spent tires $-29.2 \mathrm{MJ} / \mathrm{kg}$; municipal waste $-7-10$ $\mathrm{MJ} / \mathrm{kg}$ [Waste Statistics, 2016; Walendziewski et al, 2007].

As a research field, the incineration has already been widely investigated. It is now rather a sociological problem to solve the smooth incorporation of incineration plants into the general economy of energy supply systems for housing estates and city centers.

\section{ENERGY ORIENTED MODERNIZATION IN BUILDINGS}

Special attention is put to the thermal tests that can be carried out without destructive boring 
or hammering, without unnecessary debris or additional chemical agents put to the structures, i.e. thermal visual measurements. Although the construction sector uses energy for various purposes, heating is the one that uses the most substantial part of it, up to $60 \%$. The tests can be carried out according to the European standards based on EN 13187:1998, describing the qualitative method of investigating thermal waste by means of thermographic method. In general, these tests should be performed during the heating seasons, either inside or outside a particular compartment in the interior and the exterior of the investigated building, considering climate and atmospheric parameters, physics of tested elements and their surrounding, especially surfaces [Heim and Panek, 2008].

The presented test results show frequent inappropriateness commonly occurring in housing. Sufficient information is visible in black and white image considering the brightness of shades but usually full color spectrum is subjected to research analysis as more distinct, despite some mixing of color with the photographic image of a measured spot.

The example presented in Fig.1 shows the one of the most useful measuring techniques when the surface can reveal a hidden image of thermal flux leakage. This occurs in a historical building where the technical documentation of subsequent refurbishing and repairs is missing and thus the reliable information has been lost even within the lifespan of one generation, because the owners and administrators change quite frequently. The bright area proves the former existence of a door between the two windows. The interior has its floor comparatively low in relation to the land surface and the cold drafts from the exterior definitely must have been unbearable to the inhabitants. Moreover, the interface between the ground

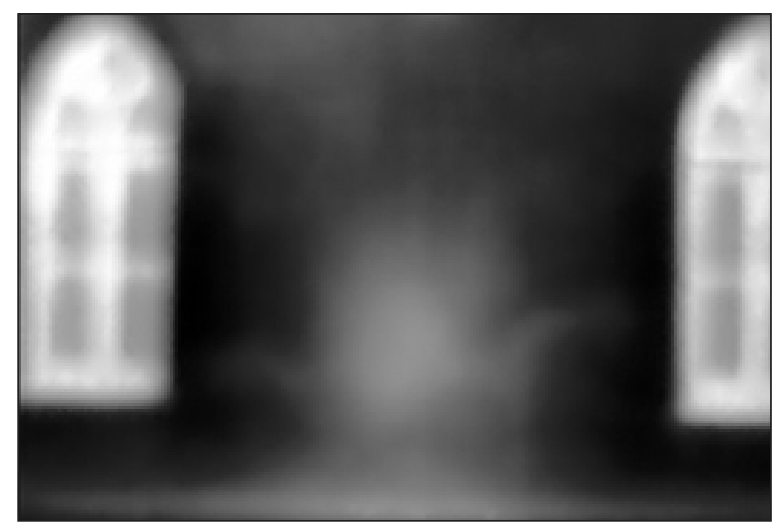

Fig. 1. Undocumented historical object and the building was not perfectly insulated due to time wear or just at manufacture. Moisture and cold definitely led the owners to make the decision remove and brick the door. The standard photo does not reveal this change because subsequent layers of plaster and paint successfully covered the wall very evenly. The brightness and the size of the area shows that the leakage of heat amount is comparable to the flux from the windows which distinctly proves that the indicated wall area needs new insulation and new finishing coating on both sides.

The next example is presented in Fig. 2, where the thermo-graphic image is taken from the interior. This figure shows typical years of neglect occurring in buildings. The wide dark lines of the ceiling show temperature difference about 10 degrees between the bright warmer surface. The vertical wall fragment is also quite cold in comparison to the main part of the ceiling. This is not a W70 panel housing construction (which could indicate a gap between panels), thus there is the evidence of poorinsulation beyond the scaffolding anchor. Moreover, there is a bright tiny pipeline over the window - this is a bleeding system for radiators. Its surface temperature however, proves it works well but should be covered anyway to avoid additional heat loss. The modernization in this room is just the matter of time and these images helped to make the decision.

Fig. 3. presents another example taken from the same historical object but emphasize the statement that the measurement taken by thermographic image can be valuable as a measurement, not only for the detection of faults. It presents the actual temperature values and indicates the spots of the highest temperature measured on the pipeline surface. If necessary, determining the temperatureof the fluid can be a matter of calcu-

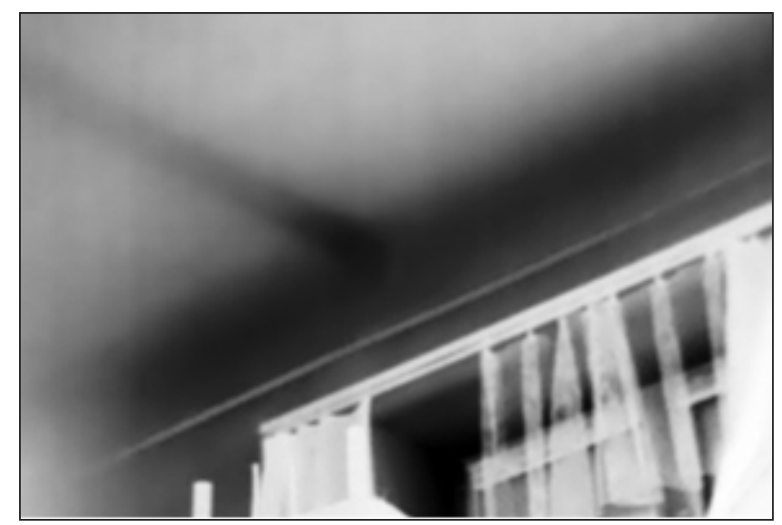

Fig. 2. Common housing thermal waste 


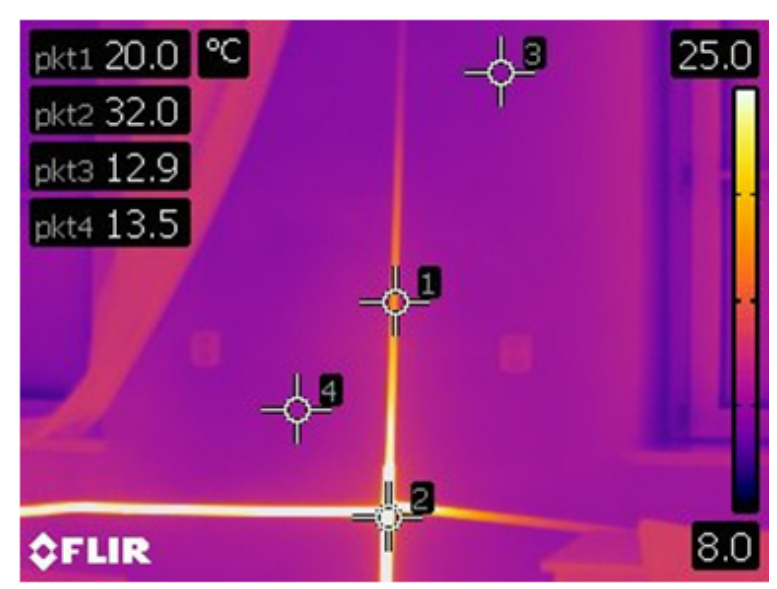

Fig. 3. Thermo-visual example of registered flow of energy in buildings

lation. It is visible that these particular calculations are correct $\left(32^{\circ} \mathrm{C}\right)$, despite the insulation is missing. What is incorrect is temperature on the wall, which is about $13^{\circ} \mathrm{C}$ in different spots. This should be about $20^{\circ} \mathrm{C}$, assuming close to the room temperature. Obviously, the lower temperature in the pipeline and the radiators (which are not visible in this image) makes that this correct value cannot be reached at the registered temperature of radiator's supply. The outflow of heat from this poorly insulated room is definitely too high [Berge 2009; Urzędowski and Wójcicka-Migasiuk, 2015; Wójcicka-Migasiuk, 2016].

Figure 4 presents a thermometry report generated form FLIR software. The report contains ambient parameters and geolocations. Another example of building motivated modernization can be presented in Fig. 5. It is actually the construction made of W70 panels. The view presents the
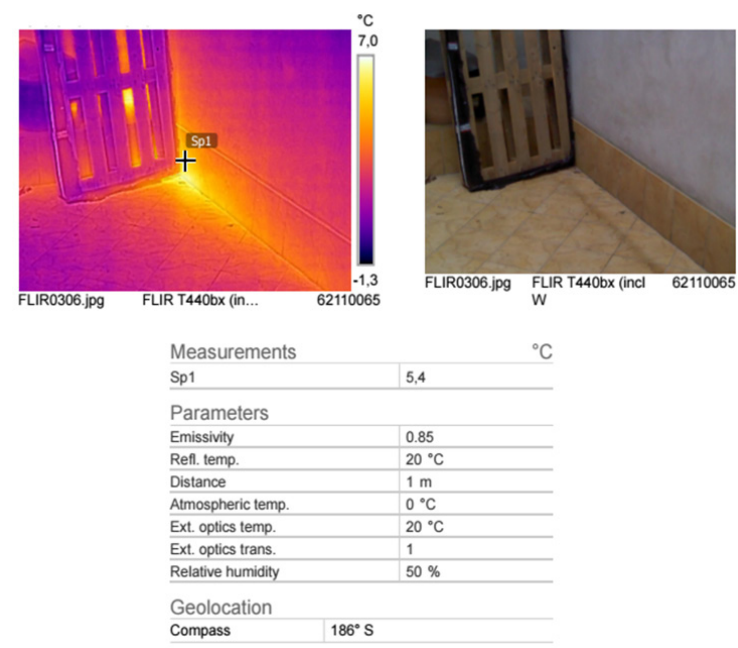

Fig. 4. Report from FLIR software northern façade where the first step of planning is to remove most of the windows and apply thick insulation assuming the appropriate internal arrangement in the building. In such case, concrete characterized by conduction about $0.1 \mathrm{~W} / \mathrm{mK}-$ available in European markets - is suggested. Total improvements include water and frost resistant plaster, polystyrene panels, application of floor heating with substantial heating renovation, including pipelines and units. The estimative range of heat demand reduction with standard methods and efficient energy conversion units is $70 \%$. The advantages of renovation versus total demolition and new construction also assume the possibility to perform some of the work gradually, with no need for high initial investments and the chance to avoid substantial long-term loans. The choice is also supported by the local cost of land.

Correct planning of modernization usually starts without specialists and the first steps and decisions are taken up by the users who often do not have even a basic knowledge on energy efficiency or investment cost justification. Rational planning occurs when it is a logic process starting from facts or knowledge. There is also a common sense forecasting based on popular conviction and well-known experience. This happens to be successful only when the experience is repeatable or a phenomenon very well-known. In other cases, it is more effective to draw on scientific forecasting and scientific methods formulated on the basis of combined analytical calculations and statistics. When building modernization is planned, the first data base should contain the climatic parameters, especially when energy passiveness is to be the direction of planning. This may not be achieved in total, but all enterprises which have this purpose in the foundation whenever the modernization is planned to a particular building or to a district, should consider the two dominating air masses, i.e. the polar one and the polar-continental one. The first is rather dominating in the form of polar-sea air from the West (60-66\% within a year) and the polar-continental air from the East (24-31\% a year) [Meteo, 2016]. A passive building should consider the influence of the first air mass bringing precipitation and clouds and the other one bringing the lowest temperatures in winter and highest in summer as well as dry air in both. That is why the walls incorporating any solar system should be oriented towards southwest, south or south-east but the northern walls should then have the minimum windows and can 


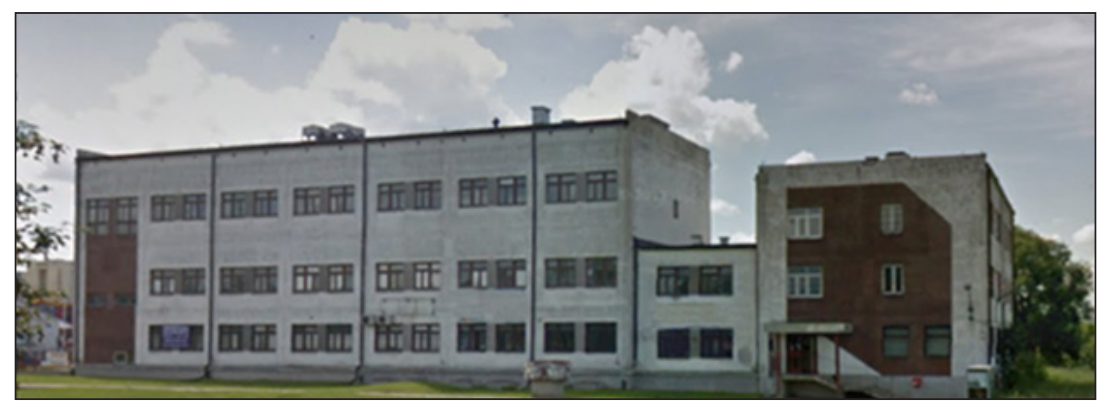

Fig. 5. W70 construction subjected to the described example of estimative analysis

be even incorporated in the ground. The building envelope cannot have thermal bridges assuming the limit of heat transfer coefficient established as low as for passive directed building: wall $u$ value $=0.15 \mathrm{~W} /\left(\mathrm{m}^{2} \mathrm{~K}\right)$, window $\mathrm{u}$ value $=0.8 \mathrm{~W} /\left(\mathrm{m}^{2} \mathrm{~K}\right)$.

The other trend in energy efficiency practice is the use of renewable energy, including solar thermal energy active systems. This is only reasonable when the heat loss from the building is possibly reduced to minimal. In general, it is necessary to know not only the climatic parameters but also the land topography, wind rose, solar direct and dispersed irradiation, as well as type of surface in the surrounding, flora in neighborhood, water and air resources. Usual efficiency of a solar thermal system $75-90 \%$ is relatively easy to reach in summer but in the Polish latitudes in winter, it drops to $10-20 \%$ of the heat demand of hot water at domestic systems. This constitutes a good opportunity for an integrated renewable, passive directed and incorporated traditional system to allow for reduced fuel consumption and to provide uninterrupted heat supply at demand, maintaining its economy at justified level. Appropriate forecasting of demand and supply adjustment cannot be overestimated here, especially when there are large differences of both. The use of solar energy usually excludes emptying houses for summer time that occurs in family houses which is different when block of flats are considered etc. Undoubtedly, sustainable development and respect for resources require some adjustments in the life style [Urzędowski and Wójcicka-Migasiuk, 2015].

\section{REGIONAL ADJUSTMENTS}

Lublin University of Technology, where this description is formulated, is located in the region of quite high solar energy availability - global yearly radiation ranges between $90-1000 \mathrm{kWh} /$ $\mathrm{m}^{2}$ when in summer it amounts to $820 \mathrm{kWh} / \mathrm{m}^{2}$ (which is usually compared to the seaside as the most privileged solar region in Poland $880 \mathrm{kWh} /$ $\mathrm{m}^{2}$ ) and in winter $260 \mathrm{kWh} / \mathrm{m}^{2}$ (seaside -280 $\mathrm{kWh} / \mathrm{m}^{2}$ ). Total insolation hours in Lublin region is about $1550 \mathrm{hrs} / \mathrm{a}$ (understood as the irradiation level above $300 \mathrm{~W} / \mathrm{m}^{2}$ ). Particular distribution in months is as follows: spring III-V $\sim 5 \mathrm{hrs}$, summer VI-VIII $\sim 7 \mathrm{hrs}$, fall IX-XI $\sim 3.5 \mathrm{hrs}$ and winter XII-II $1.5 \mathrm{hr}$ daily. The mean irradiation is then $10.25 \mathrm{MJ} / \mathrm{m}^{2} / \mathrm{d}$ and varies between $1 \mathrm{MJ} / \mathrm{m}^{2} / \mathrm{d}$ in December and $23 \mathrm{MJ} / \mathrm{m}^{2} / \mathrm{d}$ in June and July. The eastern Lublin region reaches mean annual $3800 \mathrm{MJ} / \mathrm{m}^{2}$. It is definitely worth incorporating solar system intensively, especially because there are communities which still supply household from propane-butane gas cylinders delivered by the variety of local enterprises and the lack of gas network is disadvantageous to life conditions and investments in a district community. The space heating in individual households and general public buildings is often supplied from small boiler rooms located inside such buildings. These boilers are fuelled with coal or firewood but it also happens quite often that waste is burnt for purpose. Boilers which enable to burn any kind of material including poisonous waste prevail in villages and many suburbs. Heating supply processes can be the source of air pollution with a negative influence on the human health and natural environment (including: carbon dioxide, sulphur dioxide, nitrogen oxides, dusts, organic pollution, hydrocarbons). The substantial emissions of this pollution results from the use of low efficiency boilers and low quality fuels e.g. lean coal of high content of sulfur and particularly polluting - burning of household waste. The stench in the air and smokes are the first and the most apparent result of the use of improper fuel, perceptible in the radius of even one kilometer from 
the source. The sources of so-called low emissions are difficult to identify and to eliminate but they have a substantial influence on human health and the state of environment resulting in tourism development in the area. Thus, they are harmful to the local community economy too. Unfortunately, even nowadays, throwing rubbish away by the road or in a forest, and also, the disposal of waste into surface waters is still commonly socially disregarded, often by finding poor excuses [Wójcicka-Migasiuk, 2016].

The regional aspects are also very important when an integrated system combines biofuel boilers. When preservation of resources, pro-ecological life style, energy economy and efficiency are discussed, the biofuels should be considered as well. Taking advantage of this solution one can reduce the cost of heating, increase employment, use lower quality land for agricultural production and locally reduce $\mathrm{CO}_{2}$ emission. One of the aspects which are the most important to a user is not the type of a boiler but the way of storage, or the way in which the fuel is delivered to the boiler as well as the heat generation cost. Liquid and gaseous biofuels enable fully automatic boiler supply, not much different from conventional fuels. Solid fuels can significantly differ from one another and can be more laborious in application. Decisions on particular choice of fuel result, in consequence, in special constructions of boilers serving for the purpose of a chosen fuel. There can be large chambers to combust rolled straw, typical briquette hearth with gratings or pellet feed hoppers, for example. Municipal systems usually take advantage of briquettes and pellets which are produced from wooden waste from any other timber treatment at production. It is even more energetically efficient because of the low moisture content of 6-8\%, in comparison to common timber of quite wide range between $20 \%$ and $60 \%$ depending on its type, storage and transport. Either pellets or briquettes are convenient at transport and loading but require packaging and special storage compartment to maintain low moisture content. Burners are fully automatic and direct feeding can be carried out mechanically.
Habitat districts can be provided with $50 \mathrm{~kW}$ boilers which are common in the market. The other solution could be boilers constructed for reverse combustion processes, suitable for small and medium objects, which can use chopped wood.

One of the research carried out by the authors resulted in the analysis of 3 comparative objects (called I ${ }^{\text {st }}$, II $^{\text {nd }}$, II ${ }^{\text {rd }}$ ) built as standard energy saving buildings designed with some aspects of energy passivity. The calculated quantity and cost values of substitute fuels are presented in Table 1. The geometry of the buildings and their heat demand details can be omitted in this presentation and the comparative effect is considered.

It is visible in Table 1 that in any option, pellets are the cheapest solution in all cases but the required amounts may cause some inconvenience of storage, transport and supply to boilers. The most innovative solution in technology is a condensation boiler adapted to biofuels because of a combined heating surface with a heat exchanger, where either the combustion process or the condensation occur separately but the combustion residue is generated in a combustion chamber and the exhaust fumes can condensate without a residue. Fully automatic systems meet the requirements of biofuel use and protection against atmospheric air pollution by means of correct removal of the solid residue. Taking into consideration the cleanliness of the process - the natural gas is really the cleanest at boiler combustion, thus the cleanliness of bio-oil combustion should be rather considered in relation to total $\mathrm{CO}_{2}$ emission. The comparative objects enable authors to formulate a table of exhaust fume amounts indicating the difference between bio-oil and natural gas options [Adamski et al, 2015].

Table 2 presents the average contents of exhaust calculated for selected objects, shows the comparatively clean option for natural gas combustion but at the same time gives the image how the natural source of biofuels justifies their use in comparison to gasoil which has similar exhaust but is of fossil origin with no additional green mass production.

Table 1. Comparative amounts of fuels and cost per season heating of estimated objects

\begin{tabular}{|l|c|c|c|}
\hline \multicolumn{1}{|c|}{ Substitute fuels } & $\begin{array}{c}\mathrm{Ist}^{\mathrm{st}} \\
\mathrm{kg} / \mathrm{hr} / €\end{array}$ & $\begin{array}{c}\text { II }^{\text {nd }} \\
\mathrm{kg} / \mathrm{hr} / €\end{array}$ & $\begin{array}{c}\mathrm{II} \\
\mathrm{kg} / \mathrm{hr} / €\end{array}$ \\
\hline Bio-Gasoil system & $1.45 / 1906$ & $1,86 / 2458.5$ & $2.78 / 3670.5$ \\
\hline Natural gas system & $1.26 / 1561.25$ & $1.53 / 1902.5$ & $2.33 / 2895$ \\
\hline System with pellets & $4.03 / 1452.25$ & $5.21 / 1876$ & $8.01 / 2883.5$ \\
\hline
\end{tabular}


Table 2. Annual exhaust fume production from comparative objects

\begin{tabular}{|l|c|c|c|c|c|c|}
\hline \multicolumn{1}{|c|}{ Object } & \multicolumn{2}{c|}{ Ist $^{\text {st }}$} & \multicolumn{2}{c|}{ INd $^{\text {Nd }}$} & \multicolumn{2}{c|}{ II $^{\text {rd }}$} \\
\hline Exhaust [kg/a] & bio-oil & natural gas & bio-oil & natural gas & bio-oil & natural gas \\
\hline $\mathrm{SO}_{2}$ & 3.71 & 0.067 & 5.08 & 0.062 & 6.76 & 0.094 \\
\hline $\mathrm{NO}_{2}$ & 4.36 & 3.897 & 5.97 & 0.004 & 7.95 & 0.005 \\
\hline $\mathrm{CO}$ & 1.24 & 0.769 & 1.7 & 0.001 & 2.27 & 0.001 \\
\hline $\mathrm{CO}_{2}$ & 5870.29 & 5127.04 & 8036.69 & 4.731 & 10701.03 & 7.2 \\
\hline Total suspension (TSP) & 0.74 & 0.0013 & 1.02 & 0.000001183 & 1.35 & 0.0000018 \\
\hline
\end{tabular}

\section{CONCLUSIONS}

The summary referring to conclusions resulting from integral ecology should contain formulations related to all integrated fields of knowledge. It is formulated in the aspect of the influence of motivation in energy saving undertakings. Measurable conclusions resulting directly from calculations and simulations indicate the advantages of low emission combustion, lower production of waste from households can be distinguished in each of them and their vicinity. If the forecasts are made, they may help to estimate these measurable advantages of economical effects resulting from the use and installment of low energy devices and constructions which can be meaningful to every family and local society.

There is however, a whole group of effects which are so distributed in time that their measurability, although possible, is considered time consuming and difficult.. The atmospheric pollution and environment degradation progresses slowly and thus, step by step, influence the fauna and flora in the region having an impact on our physical and psychical health.

As it follows from the calculated fuel cost, the pellet systems are the least (min. $10 \%$ ) expensive (Table 1). The exhaust pollution generated from these systems is in each case higher than the comparative fossil ones. The reason justifying the use of pellets (and other biofuels) is in their natural green production in relation to total $\mathrm{CO}_{2}$ emission.

Decisions pertaining to the use of biofuels have long term results in economy and agriculture. Boilers are constructed in relation to the type of fuel and it requires cost and efforts to change them, if theu were not previously predicted reasonably and consequently, and where the regional aspects were not properly discerned. Sustainable development of regions depends on careful and multi-criterion analyses preceded with the research of the resources which can change together with weather, climate and water conditions.
This, in turn, may result in a slowdown in the development. The presented consideration draws the attention to the necessity of better mutual adaptation of the development to the life cycle of the existing objects and their interactions in such a way that the resources do not form waste but can be rationally used up to the final life of the product.

\section{REFERENCES}

1. Adamski M, Dworecki Z, Fiszer A, Łoboda M, Niedbała G, 2015. Comparative analysis of energy contents in fuels (in Polish), Uniwersytet Przyrodniczy w Poznaniu, Instytut Bioinżynierii Systemów, Poznań, http://www.pimr.poznan.pl. Access Dec. 2015.

2. Berge B. 2009. The ecology of building materials. Second edition, Architectural Press, p. 30, 254-256, 289.

3. Heim D., Panek A. 2008. The basis for the month balance metod to determine energy demand for heat and cooling In the relation to the directive of EPBD, (in Polish) in Energia i Budynek, 1(11), 22-28.

4. http://ec.europa.eu/eurostat/statistics-explained/index.php/Waste_statistics. Access Dec. 2016.

5. http://meteo.ftj.agh.edu.pl/meteo Access Dec. 2016.

6. Urzędowski A., Wójcicka-Migasiuk D. 2015. Visual analysis of heat transport in unique object. Advances in Science and Technology Res. J. 28(9), 153-159.

7. Walendziewski J., Kułażyński M., Surma A. 2007. Waste potential and their types for fuel production (in Polish) Sieć Naukowo- Gospodarcza "Energia" Wrocław, http://www.energia.dczt.wroc.pl/files/ Określenie\%20potencjału\%20odpadów.pdf, Access Apr. 2017.

8. Wójcicka-Migasiuk D. 2016. The influence of proecological behavior on life style in Polish conditions (in Polish) In: Humanistyka a nauki ścisłe, ed. Halina Rarot, Politechnika Lubelska, Monografie 2016, p. 43-69.

9. Zielina-Radziszewska E. 2017. The evaluation of thermal renovations of buildings - pros and cons - the most frequent errors, (in Polish). Przegląd Budowlany, 9(42), 45-48. 